\title{
Immune Regulation, Maternal Infection, Vaccination, and Pregnancy Outcome
}

\author{
Mercy PrabhuDas, PhD, Jeanna M. Piper, MD, \\ Patrick Jean-Philippe, MD, ${ }^{1}$ and Marrah Lachowicz-Scroggins, $\mathrm{PhD}^{2}$
}

\begin{abstract}
About $12.5 \%$ of all maternal deaths in the United States are due to infectious causes. This proportion, although stable during the past three decades, represents an increase in infectious causes of mortality, as the overall mortality rate in U.S. pregnant women had increased steadily during that same period. During healthy pregnancies, a delicate immunological balance - in which a mother's immune system tolerates the semi-allogeneic fetus yet maintains immune competency against infectious agents-is achieved and maintained. This immunological paradigm, however, results in increased susceptibility to infectious diseases during pregnancy, particularly in later stages and during the early postpartum period. The inflammatory process induced by these infectious insults, as well as some noninfectious insults, occurring during pregnancy can disrupt this carefully achieved balance and, in turn, lead to a state of rampant inflammation, immune activation, and dysregulation with deleterious health outcomes for the mother and fetus. Elucidating mechanisms contributing to the disruption of this immunologic homeostasis, and its disruption by infectious pathogens, might offer opportunities for interventions to reduce maternal and fetal morbidity and mortality.
\end{abstract}

Keywords: pregnancy, infections, immunity, inflammation

\section{Immune Landscape in Pregnancy}

$\mathbf{M}$ ULTIPLE INNATE AND adaptive immune mechanisms coordinate and regulate the balance during placentation, pregnancy maintenance, and parturition. A successful pregnancy depends on the ability of the maternal immune system to adapt to each developmental stage. Mor and colleagues ${ }^{1,2}$ proposed (i) a pro-inflammatory stage associated with implantation, (ii) a second anti-inflammatory stage associated with fetal growth, and (iii) another pro-inflammatory stage that is responsible for initiating parturition. The stages of pregnancy from implantation to parturition are vulnerable to complications that result from host intrinsic or extrinsic conditions that might have negative consequences for the pregnant woman, fetus, or both. Insufficient maternal artery remodeling could lead to preeclampsia (PE), intrauterine growth restriction, and recurrent pregnancy loss. ${ }^{3,4}$ On the contrary, excessive placental invasion can result in maternal anemia and postpartum hemorrhage. We discuss the role of immune cells and effectors in regulating processes during pregnancy and how inflammatory perturbations, such as infections, can affect placental development. Responses to multiple antigens, including fetal and paternal antigens, noninherited maternal antigens, commensals, or infectious agents, are constantly being regulated to ensure successful pregnancy outcomes.

The placenta forms the primary barrier between the fetal and maternal compartments throughout pregnancy. In humans, it forms within 5-6 days post-fertilization. By 10-12 weeks of gestation, remodeling of the maternal circulation occurs by the formation of spiral arteries, and maternal blood is now in contact with the placenta. ${ }^{5}$ Extravillous trophoblasts invade the decidua basalis, anchoring the placenta into the uterine implantation site, where they are in juxtaposition to maternal immune cells. Approximately $40 \%$ of the decidua is composed of maternal leukocytes. In the first trimester, decidual natural killer (dNK) cells compose the majority (around 70\%) of immune cells, macrophages compose $20 \%-$ $25 \%$, and $\mathrm{T}$ cells compose $3 \%-10 \%$.

\footnotetext{
${ }^{1}$ National Institute of Allergy and Infectious Diseases, National Institutes of Health, Rockville, Maryland, USA.

${ }^{2}$ National Heart, Lung, and Blood Institute, National Institutes of Health, Bethesda, Maryland, USA.

(c) Mercy PrabhuDas et al. 2021; Published by Mary Ann Liebert, Inc. This Open Access article is distributed under the terms of the Creative Commons Attribution Noncommercial License (http://creativecommons.org/licenses/by-nc/4.0/) which permits any noncommercial use, distribution, and reproduction in any medium, provided the original author(s) and the source are cited.

Correction added on February 19, 2021 after first online publication of November 24, 2020: The article reflects Open Access, with copyright transferring to the author(s), and a Creative Commons Attribution Noncommercial License (CC-BY-NC) added (http:// creativecommons.org/licenses/by-nc/4.0/).
} 


\section{Macrophages}

Decidual macrophages are differentiated from bone marrowderived macrophages that migrate from the bloodstream to the uterus during the pre-implantation period and differentiate into decidua-specific macrophages on exposure to the local microenvironment. ${ }^{6,8}$ They serve as the primary antigenpresenting cells in early pregnancy and have been reported to play a regulatory, homeostatic, and anti-inflammatory role. ${ }^{6}$ Functions of decidual macrophages include the remodeling of spiral arteries and trophoblast invasion; phagocytosis of apoptotic trophoblasts to prevent the activation of proinflammatory pathways in the decidua; the production of indoleamine 2,3-dioxygenase, which catabolizes tryptophan and hinders $\mathrm{T}$ cell activation; and protection of the fetus against infections as demonstrated by the expression of pattern recognition receptors, including CD163, CD206, and CD209.9 Macrophages also support the vascular network needed for corpus luteum integrity and the production of progesterone, which is essential for establishing a pregnancy. ${ }^{10}$ Zhang et al. ${ }^{8}$ recently demonstrated that soluble PD-L1 produced by trophoblasts contributes to macrophage polarization toward the M2 regulatory phenotype, decreasing inflammation.

\section{Natural killer cells}

Natural killer (NK) cells are the most abundant lymphocytes (50\%-70\% of decidual lymphocytes) present in the uterus at the maternal-fetal interface and have been reported to be involved in spiral artery remodeling to keep up with the nutritional demands of the fetus. dNK cells display limited cytotoxicity but secrete cytokines, growth factors, and angiogenic factors required to remodel maternal spiral arteries, promote angiogenesis, and attract trophoblasts to invade the decidua. Interferongamma (IFN- $\gamma$ ) secreted by uterine NK cells act on endothelial cells and decidual stromal cells; however, the pathway that stimulates IFN- $\gamma$ production and other aspects of remodeling have yet to be elucidated. ${ }^{11}$ One of the genes that is upregulated in $\mathrm{dNK}$ cells is galectin-1, which induces apoptosis of activated CD8 $\mathrm{T}$ cells and induces differentiation of helper T cells to a Th2 cytokine profile. ${ }^{12}$ A unique subset of dNK cells was identified in repeated pregnancies and not in first pregnancies. These dNK cells had a unique transcriptome and epigenetic signature that might contribute to improved placentation in pregnancies beyond the first pregnancy because of previous priming and memory that aids in vascular remodeling. This population was termed pregnancy-trained dNK cells. ${ }^{13}$

\section{T cells}

In addition to dNK cells, decidual CD8 T (dCD8T) cells are important cytolytic effector cells present at the maternalfetal interface. These dCD8T cells are present in a low proportion $(2 \%-7 \%)$ of leukocytes in first-trimester decidua; however, their proportion increases to $30 \%$ in term pregnancy decidua. They have an effector-memory phenotype but have reduced expression of perforin and granzyme B proteins when compared with peripheral blood CD8 $\mathrm{T}$ cells. ${ }^{14}$ These dCD8T cells might be specific for several antigens, including major histocompatibility complex (MHC) molecules of paternal origin (HLA-C expressed by extravillous trophoblasts), minor histocompatibility antigens, or pathogen-derived antigens. Despite specificity for paternal MHC and minor histocompatibility antigens, a compromise in pregnancy outcome is not evident. ${ }^{14}$ The lack of response to these disparate antigens might include the presence of a high proportion of regulatory $\mathrm{T}$ cells (Tregs), the contribution of cytokine-like transforming growth factor- $\beta$ and interleukin-10, and hormones such as progesterone that regulate $\mathrm{T}$ cell activation. ${ }^{15}$

\section{Additional factors}

Additional avenues by which tolerance is promoted at the maternal-fetal interface include the activation of an epigenetic program that excludes immune cells through gene silencing of key Th1-attracting chemokines, CXCL9, CXCL10, CXCL11, and $\mathrm{CCL}^{16}$; maintenance of low numbers of dendritic cells that can migrate to uterine lymph nodes, ${ }^{17}$ minimizing potentially immunogenic $\mathrm{T}$ cell responses to fetal and placental antigens; reduction of complement deposition ${ }^{18}$; and transfer of maternal cells to the fetal thymus and peripheral lymphoid tissues to prime tolerogenic responses. In early pregnancy, fetal cells are found in maternal blood, and maternal cells are found in human fetal tissues beginning in the second trimester of pregnancy and are retained long term after pregnancy. ${ }^{19}$ Understanding and uncovering the factors that instruct tissue-specific homing of these cells, and the need for inflammatory mediators and/or growth factors to proliferate and acquire tolerogenic properties, will assist in establishing the role of microchimeric cells in driving the expansion of Treg populations in pregnancy and beyond.

\section{Inflammation and Infections During Pregnancy}

\section{Complications of maternal respiratory infections}

Pregnancy predisposes women to increased risk and cases of respiratory infections and pneumonia, with the same pathogens present in nonpregnant women. ${ }^{20}$ Physiologic changes to accommodate a growing fetus, changes in oxygen consumption, reduced numbers of key immune cells, aspiration during delivery, and presence of other comorbidities were identified as risk factors for pneumonia in pregnant women. ${ }^{21}$ Seasonal/pandemic influenza and pandemic coronavirus infections are associated with significant morbidity and mortality. ${ }^{22,23}$

Influenza. Influenza infection during pregnancy is a risk for acute respiratory distress syndrome (ARDS). In a study of 2,808 pregnant women who underwent mechanical ventilation for ARDS, influenza was a risk factor for death, with a $9 \%$ mortality rate observed. ${ }^{24}$ Maternal vaccination also protects the fetus/infant, as maternal antibodies can be passed transplacentally and via breast milk, ${ }^{25}$ which protects infants younger than 1 year, who are more susceptible to the virus and are too young to be vaccinated. ${ }^{26}$

MERS, SARS-CoV, and SARS-CoV-2. Increased susceptibility to infection during pregnancy puts women at risk for rapid respiratory failure during coronavirus infection. Outcomes analysis of cases of SARS-CoV, MERS, and SARS-CoV2 indicated that all have a high risk of hospitalization, placement on mechanical ventilation, preterm birth, and fetal complications. ${ }^{27,28}$ Early analysis of 38 maternal cases of SARS-CoV2, however, indicates no maternal deaths, unlike previous data on SARS-CoV and MERS in pregnancy. ${ }^{29}$ 


\section{Complications of maternal systemic, placental, and urogenital infections}

Maternal HIV infection is associated with unique prenatal and postnatal concerns. ${ }^{30}$ HIV infection is associated with increased risk for cervical dysplasia and cancer, indicating a need for regular screening in patients who are HIV-positive. ${ }^{31}$ Monitoring and supporting adherence to antiretroviral drugs to reduce transmission during pregnancy is also important in antenatal care. During pregnancy, HIV infection is associated with elevated blood pressure and PE. Imbalance of two circulating factors associated with PE, follistatin and granulocyte-colony stimulating factor, could serve as a possible biomarker for PE in women with HIV. ${ }^{32}$

The placenta plays a key role in vertical transmission from mother to fetus, and infections are important causes of morbidity and mortality, particularly for the fetus. Infections include Toxoplasma gondii, syphilis, Listeria monocytogenes, malaria, parvovirus B19, Zika virus, rubella virus, human cytomegalovirus (HCMV), and herpes simplex virus (HSV). ${ }^{33}$ Ureaplasma in the family Mycoplasmataceae are part of commensal bacteria in the urogenital tract flora. Infection with Ureaplasma, however, is a common cause of culture-positive chorioamnionitis, ${ }^{34}$ a pro-inflammatory, highly cellular infection associated with preterm birth and poor fetal outcomes. ${ }^{35}$ Maternal infections can result in sepsis with poor clinical outcomes. Escherichia coli, Streptococcus pneumoniae, and Streptococcus pyogenes infections can result in sepsis and toxic shock in both the prenatal and antenatal period. ${ }^{36}$ S. pyogenes (Group A Streptococcus) sepsis rates in the postpartum period are rising because of the emergence of more virulent strains in the past two decades. ${ }^{37}$

Toxoplasmosis. Toxoplasmosis is a protozoan infection from feline hosts, common in underresourced settings. Pregnant women are vulnerable to infection and often are undiagnosed, because only $10 \%-20 \%$ of infected mothers present with symptoms; this infection can cause severe congenital defects if not treated. ${ }^{38}$ Toxoplasmosis can be treated in pregnancy, but the aggressive treatment regimen is performed after polymerase chain reaction confirmation of fetal infection from amniotic fluid. ${ }^{39}$

Syphilis. Syphilis caused by Treponema pallidum, a spirochete, is the third most common sexually transmitted disease. Treatment within 30 days of delivery eliminates most cases of congenital syphilis infection. Despite highly effective treatment, an estimated 2 million new cases of congenital syphilis are reported annually worldwide. ${ }^{40}$ Recent alarming increases in the United States are significantly associated with stillborn deaths and other fetal complications. $^{41,42}$

Listeria monocytogenes. Listeriosis results from severe blood-borne infections with a rod-shaped gram-positive bacterium in contaminated food. Infection in adults is mild but can be debilitating in pregnant women, resulting in maternal mortality, fetal infection, and demise. ${ }^{43}$

Malaria and other vector-borne infections. Malaria is caused by four protozoan parasites, and studies suggest that as many as $25 \%$ of maternal deaths in endemic areas are due to severe malarial disease or co-infection with human immunodeficiency virus/acquired immunodeficiency syndrome. ${ }^{44}$ Prevention strategies in endemic areas include bed nets, insecticides, and prophylactic treatment with antimalarial drugs, but adherence to these strategies is poor. Malarial infection during pregnancy results in poor fetal outcomes, risk of infant malaria, and potential multiorgan failure in the mother. ${ }^{45}$ Severe anemia and thrombocytopenia are risks during pregnancy for women with malaria. PE with hemolysis, elevated liver enzymes, and low platelet count (HELLP) syndrome are common causes of thrombocytopenia in these cases. ${ }^{46}$

Parvovirus B19. Although uncommon in pregnancy, the single-stranded DNA virus parvovirus B19 causes the childhood infection, erythema infectiosum, dubbed "fifth disease." When maternal infection occurs, it increases the risk of fetal loss and hydrops. ${ }^{47}$ Large-scale screening for immunity to parvovirus is not part of clinical guidelines, because two-thirds of adults are immune. ${ }^{48}$

Zika virus. Zika virus is a positive-sense single-stranded RNA virus that is antigenically similar to other members of the family Flaviviridae, such as dengue, yellow fever, and West Nile virus. ${ }^{49}$ Most patients infected with Zika virus are asymptomatic, but maternal infection results in fetal loss and neurological abnormalities. ${ }^{50}$ No treatment is available, and given the severe fetal outcomes, vaccine trials are underway. ${ }^{51}$

Rubella virus. Rubella is a vaccine-preventable infection resulting from RNA virus from the Togaviridae family. Unvaccinated mothers present with early, mild respiratory irritation leading to widespread rash and joint pain. ${ }^{52}$ Infection during pregnancy, up to 20 weeks, can result in fetal defects in as many as $90 \%$ of cases, including defects in vision, hearing, and heart, as well as cognitive deficits. ${ }^{53}$

Human cytomegalovirus. Currently, no safe or effective treatments exist for maternal HCMV infection to prevent fetal transmission. Recommendations include universal screening, prevention, hygiene education, and diagnosis of maternal HCMV infection to mitigate the significant consequences for the fetus. ${ }^{54}$ Although no vaccines exist currently for HCMV, modification of the most efficacious MF59adjuvanted glycoprotein B (gB) protein subunit vaccine (gB/MF59) is underway in preclinical models. ${ }^{55}$

Herpes simplex virus. HSV neonatal infection is rare but can result in fetal neurological impairment. ${ }^{56}$ Maternal transfer of immunoglobuloin $\mathrm{G}$ antibodies crossing the placenta offers a natural form of protection to the fetus; the highest risk to the fetus occurs when maternal infection and shedding are active close to delivery. ${ }^{57}$ Clinical trials for HSV vaccines have failed to meet their endpoint for the prevention of adult-to-adult transmission, ${ }^{58}$ but evidence suggests that maternal vaccination might protect infants from infection. Studies in mice using a replicationdefective HSV-2 vaccine candidate, d15-29, protected pups from infection after intranasal HSV challenge 1-2 days postpartum. ${ }^{59}$ 
Ureaplasma. Potential causes for virulence and intraamniotic infection with Ureaplasma are changes in the lipoprotein multiple-banded antigen isolates detected in preterm birth ${ }^{60}$ Imbalance of lactobacilli in the vaginal tract increases vaginal $\mathrm{pH}$, promoting infections from the vagina into the amniotic cavity. Such isolates as Ureaplasma urealyticum with higher urease activity increase $\mathrm{pH}$, causing infections locally. ${ }^{61}$

\section{Infectious Complications Specific to Pregnancy}

\section{Septic abortion}

Septic abortion is an infection of the products of conception (POC [e.g., fetus, placenta, membranes]) in early pregnancy, before fetal viability. It occurs most commonly after the incomplete evacuation of a spontaneous or induced abortion, in which some or all of the POC remain in the uterine cavity and become infected by ascending polymicrobial vaginal flora. ${ }^{62,63}$ Clinical signs include high fever, severe abdominal pain/cramping, and foul-smelling vaginal discharge. ${ }^{62}$ Before legalized pregnancy termination, septic abortion was a frequently reported complication of unsafe abortion with high rates of maternal mortality. ${ }^{63}$ Septic abortion is now rare in the developed world but continues to be a major cause of maternal morbidity and mortality in developing countries. ${ }^{63}$

Septic abortion is diagnosed based on fever and uterine tenderness and is treated by prompt removal of any remaining POC and administration of broad-spectrum antibiotics. ${ }^{6,64}$ The uterus might be softened by the infection, increasing the risk of uterine perforation or uterine atony, which might require a hysterectomy. Pelvic abscess formation is also a risk and could result in hysterectomy and, potentially, salpingectomy and oophorectomy. ${ }^{65}$

A less common cause of intrauterine infection very early in pregnancy (before complete occlusion of the uterine cavity) is ascending infection (Neisseria gonorrhoeae, Chlamydia trachomatis, or other organisms) resulting in pelvic inflammatory disease (PID). Inpatient treatment is recommended for pregnant women with PID, and ectopic pregnancy must be ruled out. ${ }^{66}$

\section{Intraamniotic infection}

Intraamniotic infection (IAI, chorioamnionitis) involves inflammation of amniotic fluid, placenta, fetus, membranes, or decidua ${ }^{67}$ It is typically polymicrobial and occurs after rupture of membranes due to ascending vaginal bacteria, ${ }^{68}$ but it can infrequently occur with intact membranes via ascending infection (mycoplasmas) or hematogenous spread (L. monocytogenes) ${ }^{69}$ Organisms might or might not be detected in the amniotic fluid. ${ }^{70}$ Pathologic examination of placenta and membranes identifies cases with histologic inflammation, which could occur without clinical disease. ${ }^{69}$

The IAI is a common complication of prolonged rupture of membranes before or during labor at term (2\%-5\% of deliveries) ${ }^{67}$ and is very frequent (up to $70 \%$ ) with preterm premature rupture of membranes. ${ }^{69}$ Prolonged labor, particularly in the second stage, is also strongly associated with IAI. ${ }^{69}$

The diagnosis of IAI was recently updated to include three categories. ${ }^{71}$ Category 1 (isolated maternal fever) is defined as a single oral temperature of $\geq 39^{\circ} \mathrm{C}$ or persistent $38^{\circ} \mathrm{C}-$ $38.9^{\circ} \mathrm{C}$ continuing for 30 minutes. Category 2 (suspected IAI) is maternal intrapartum fever (Category 1) with maternal leukocytosis $\left(>15,000 / \mathrm{mm}^{3}\right)$, purulent cervical discharge, or fetal tachycardia. Category 3 (confirmed IAI) is a positive amniotic fluid test result (gram stain, glucose level, or culture results consistent with infection) or placental pathology demonstrating histologic placental infection or inflammation. Treatment is recommended for Categories 2 and 3 plus Category 1 with fever $\geq 39^{\circ} \mathrm{C}$ and should be considered for $38^{\circ} \mathrm{C}-38.9^{\circ} \mathrm{C}$ with no other obvious cause. ${ }^{67}$

The IAI typically responds well to prompt antibiotic treatment and fever reduction but might contribute to uterine atony, resulting in failure to progress in labor (requiring labor augmentation and potentially cesarean delivery) and postpartum hemorrhage after delivery. ${ }^{69}$ Antibiotics usually are discontinued at the time of delivery unless risk factors for postpartum endometritis (PPE) are present-most notably cesarean delivery, when at least one postpartum dose is recommended. ${ }^{67}$ Infants also are typically assessed for neonatal sepsis after delivery.

\section{Postpartum endometritis}

PPE is intrauterine infection with onset after delivery. It is typically polymicrobial and might progress to sepsis and maternal death. PPE occurs more frequently after cesarean delivery ( $>20$-fold increased risk), particularly after prolonged labor or ruptured membranes (historical rates $>25 \%){ }^{64,72}$ Antibiotic prophylaxis after cord clamping (avoiding infant exposure) reduced PPE by $60 \%$ to $70 \%,{ }^{72}$ and preoperative antibiotic prophylaxis (before skin incision) reduced rates by an additional $40 \%-50 \% .^{73,74}$ Vaginal cleansing in addition to surgical skin preparation might also reduce postoperative infection rates. ${ }^{75}$ The diagnosis of PPE is clinical, based on fever together with uterine tenderness or hypotonia and foul vaginal discharge. ${ }^{64}$ Broad-spectrum antibiotic treatment is typically effective. ${ }^{76}$

\section{Wound infections}

Wound infections after cesarean delivery are also common, particularly after prolonged labor and/or IAI. In the absence of antibiotic prophylaxis, rates exceeded $10 \%$ but have been reduced to $2 \%-3 \%$ with current prophylaxis procedures. ${ }^{72,73}$ In addition to antibiotic prophylaxis, preoperative vaginal cleansing, use of subcuticular sutures instead of staples, and negative pressure dressings might further reduce cesarean wound complications. ${ }^{77}$ Episiotomy/perineal laceration infections were diagnosed in 5\% of primiparas in a recent cohort study with focused examination $2-3$ weeks post partum, with risks increased by obesity and reduced by antibiotics in labor or postpartum. ${ }^{78}$ A rare, but more serious, form of postpartum wound infection is necrotizing fasciitis, which has been reported after cesarean section, episiotomy, and even postpartum tubal ligation procedures. ${ }^{79}$

\section{Septic pelvic thrombophlebitis}

Septic pelvic thrombophlebitis is an uncommon postpartum complication $(<0.1 \%)$ that typically occurs in women with chorioamnionitis or endometritis, particularly after cesarean delivery (6- to 10-fold higher than vaginal delivery). ${ }^{80}$ 
Septic pelvic thrombophlebitis is often a diagnosis of exclusion typically associated with prolonged febrile illness $(>3$ days) that is unresponsive to broad-spectrum antibiotics with no other obvious source, but it can be confirmed by visualization of a thrombus in pelvic veins by computed tomography or magnetic resonance imaging. Septic pelvic thrombophlebitis is treated with prolonged broad-spectrum antibiotic coverage with or without the addition of anticoagulation. ${ }^{81}$ Thrombophilia might play a role, because a recent cohort study reported an association with deep venous thrombosis (9\%) and pulmonary emboli (7\%). ${ }^{80}$ Mortality, which once exceeded $50 \%$, is now rare, with none reported in recent case series and cohort studies. ${ }^{80,81}$

\section{Vaccination Against Maternal and Fetal Infections}

Studies in mice show that the gene signatures of innate immune responses to vaccination in pregnant and nonpregnant mice were not affected by pregnancy, suggesting that boosting immune responses through adjuvants is safe and effective. ${ }^{82}$ The World Health Organization's Global Advisory Committee on Vaccine Safety found no adverse pregnancy outcomes associated with common vaccines. ${ }^{83}$ Systematic barriers, however, prevent implementation of vaccination programs and compliance with prenatal vaccination recommendations. ${ }^{84}$ Maternal preference for certain vaccines is a factor in adherence to recommendations during prenatal care. A large cross-sectional study designed to monitor rates of prenatal vaccination found higher rates of pertussis vaccination when compared with influenza. ${ }^{85}$ Maternal preference to select vaccinations with a perceived benefit to their child, versus one that confers a benefit to themselves in addition to negative perceptions for the influenza vaccine, might contribute to lower adherence rates when compared with pertussis and combination Tdap vaccination. ${ }^{86,87}$

\section{Gains, Gaps, Challenges, and the Future}

Since the concept of general maternal immune suppression during pregnancy as a means of immune tolerance toward the fetus was first postulated more than 50 years ago, ${ }^{88}$ an impressive body of knowledge has accumulated, and the field has seen major advances in elucidating immune processes at play in maintaining maternal tolerance of fetal antigens and immune homeostasis, their disturbances, and resulting inflammation and immune dysregulation. This has paved the way for such interventions as low-dose aspirin to improve health outcomes for mother and fetus. ${ }^{89,90}$ Significant gaps in our understanding, however, persist, and renewed research efforts are needed. Recent advances in molecular and other research tools provide powerful means to bring new insights into these complex processes that could have predictive value in early identification of pregnancies at risk for adverse outcomes and open the door to potential preventive and therapeutic approaches. ${ }^{91,92}$ Because $12.5 \%$ of the estimated 700 maternal deaths occurring yearly in the United States are due to infectious causes, and a greater number of deaths and other adverse maternal and fetal outcomes are due to noninfectious conditions caused by inflammation, ${ }^{93,94}$ gaining such an understanding will be critical in generating countermeasures and reversing this increasing mortality trend.

\section{Conclusion}

Aberration of immune responses during pregnancy could lead to pregnancy complications and congenital abnormalities, as well as an increased propensity for infections. Multiple developmental programs facilitate and coordinate immune responses during pregnancy. The molecular components yet to be elucidated could uncover (i) novel insights into the immunological properties of the decidua and interactions between the fetus and pregnant woman, (ii) an improved understanding of the pathogenesis of pregnancy complications, and (iii) how such interactions determine maternal and child health.

\section{Author Disclosure Statement}

No competing financial interests exist.

\section{Funding Information}

No funding was received for this article.

\section{References}

1. Mor G, Cardenas I. The immune system in pregnancy: A unique complexity. Am J Reprod Immunol 2010;63:425433.

2. Mor G, Cardenas I, Abrahams V, Guller S. Inflammation and pregnancy: The role of the immune system at the implantation site. Ann N Y Acad Sci 2011;1221:80-87.

3. Tessier DR, Yockell-Lelièvre J, Gruslin A. Uterine spiral artery remodeling: The role of uterine natural killer cells and extravillous trophoblasts in normal and high-risk human pregnancies. Am J Reprod Immunol 2015;74:1-11.

4. Yockey LJ, Iwasaki A. Interferons and proinflammatory cytokines in pregnancy and fetal development. Immunity 2018;49:397-412.

5. Arora N, Sadovsky Y, Dermody TS, Coyne CB. Microbial vertical transmission during human pregnancy. Cell Host Microbe 2017;21:561-567.

6. Liu S, Diao L, Huang C, Li Y, Zeng Y, Kwak-Kim JYH. The role of decidual immune cells on human pregnancy. J Reprod Immunol 2017;124:44-53.

7. Manaster I, Mandelboim O. The unique properties of uterine NK cells. Am J Reprod Immunol 2010;63:434-444.

8. Zhang YH, Aldo P, You Y, et al. Trophoblast-secreted soluble-PD-L1 modulates macrophage polarization and function. J Leukoc Biol 2020; [Epub ahead of print]; DOI: 10.1002/JLB.1A0420-012RR.

9. Ander SE, Diamond MS, Coyne CB. Immune responses at the maternal-fetal interface. Sci Immunol 2019;4:eaat6114.

10. Care AS, Diener KR, Jasper MJ, Brown HM, Ingman WV, Robertson SA. Macrophages regulate corpus luteum development during embryo implantation in mice. J Clin Invest 2013;123:3472-3487.

11. Sojka DK, Yang L, Yokoyama WM. Uterine natural killer cells. Front Immunol 2019;10: [Epub ahead of print]; DOI: 10.3389/fimmu.2019.00960.

12. Kopcow HD, Rosetti F, Leung Y, Allan DS, Kutok JL, Strominger JL. T cell apoptosis at the maternal-fetal interface in early human pregnancy, involvement of galectin1. Proc Natl Acad Sci U S A 2008;105:18472-18477.

13. Gamliel M, Goldman-Wohl D, Isaacson B, et al. Trained memory of human uterine NK cells enhances their function in subsequent pregnancies. Immunity 2018;48:951962.e955. 
14. Crespo ÂC, van der Zwan A, Ramalho-Santos J, Strominger JL, Tilburgs T. Cytotoxic potential of decidual NK cells and CD8+ T cells awakened by infections. J Reprod Immunol 2017;119:85-90.

15. Tilburgs T, Schonkeren D, Eikmans M, et al. Human decidual tissue contains differentiated CD8+ effector-memory $\mathrm{T}$ cells with unique properties. J Immunol 2010;185:4470 4477.

16. Nancy P, Tagliani E, Tay CS, Asp P, Levy DE, Erlebacher A. Chemokine gene silencing in decidual stromal cells limits $\mathrm{T}$ cell access to the maternal-fetal interface. Science 2012;336:1317-1321.

17. Erlebacher A. Immunology of the maternal-fetal interface. Annu Rev Immunol 2013;31:387-411.

18. Mellor AL, Sivakumar J, Chandler P, et al. Prevention of T cell-driven complement activation and inflammation by tryptophan catabolism during pregnancy. Nat Immunol 2001;2:64-68.

19. Kinder JM, Stelzer IA, Arck PC, Way SS. Immunological implications of pregnancy-induced microchimerism. Nat Rev Immunol 2017;17:483-494.

20. Mehta N, Chen K, Hardy E, Powrie R. Respiratory disease in pregnancy. Best Pract Res Clin Obstet Gynaecol 2015; 29:598-611.

21. Brito V, Niederman MS. Pneumonia complicating pregnancy. Clin Chest Med 2011;32:121-132.

22. Mullins E, Evans D, Viner RM, O'Brien P, Morris E. Coronavirus in pregnancy and delivery: Rapid review. Ultrasound Obstet Gynecol 2020;55:586-592.

23. Oboho IK, Reed C, Gargiullo P, et al. Benefit of early initiation of influenza antiviral treatment to pregnant women hospitalized with laboratory-confirmed influenza. J Infect Dis 2016;214:507-515.

24. Rush B, Martinka P, Kilb B, McDermid RC, Boyd JH, Celi LA. Acute respiratory distress syndrome in pregnant women. Obstet Gynecol 2017;129:530-535.

25. Misra RS, Nayak JL. The importance of vaccinating children and pregnant women against influenza virus infection. Pathogens 2019;8: [Epub ahead of print]; DOI: 10.3390/ pathogens8040265.

26. Committee on Infectious Dieases. Recommendations for Prevention and Control of Influenza in Children, 20182019. Pediatrics 2018; 142:e20182367.

27. Dashraath P, Jing Lin Jeslyn W, Mei Xian Karen L, et al. Coronavirus disease 2019 (COVID-19) pandemic and pregnancy. Am J Obstet Gynecol 2020;222:521-531.

28. Schwartz DA, Graham AL. Potential maternal and infant outcomes from (Wuhan) coronavirus 2019-nCoV infecting pregnant women: Lessons from SARS, MERS, and other human coronavirus infections. Viruses 2020;12: [Epub ahead of print]; DOI: 10.3390/v12020194.

29. Schwartz DA. An analysis of 38 pregnant women with COVID-19, their newborn infants, and maternal-fetal transmission of SARS-CoV-2: Maternal coronavirus infections and pregnancy outcomes. Arch Pathol Lab Med 2020; [Epub ahead of print]; DOI: 10.5858/arpa.20200901-SA.

30. Berhie S, Yee L, Jao J. The reproductive years of women with perinatally acquired HIV: From gynecologic care to obstetric outcomes. Infect Dis Clin North Am 2019;33: 817-833.

31. Ghebre RG, Grover S, Xu MJ, Chuang LT, Simonds H. Cervical cancer control in HIV-infected women: Past, present and future. Gynecol Oncol Rep 2017;21:101-108.
32. Mdlalose S, Moodley J, Naicker T. The role of follistatin and granulocyte-colony stimulating factor in HIVassociated pre-eclampsia. Pregnancy Hypertens 2020;19: 81-86.

33. Costa ML, de Moraes Nobrega G, Antolini-Tavares A. Key infections in the placenta. Obstet Gynecol Clin North Am 2020;47:133-146.

34. Oh KJ, Kim SM, Hong J-S, et al. Twenty-four percent of patients with clinical chorioamnionitis in preterm gestations have no evidence of either culture-proven intraamniotic infection or intraamniotic inflammation. Am J Obstet Gynecol 2017;216:604.e1-604.e11.

35. Galaz J, Romero R, Xu Y, et al. Cellular immune responses in amniotic fluid of women with preterm clinical chorioamnionitis. Inflamm Res 2020;69:203-216.

36. Morgan M. Challenging infections in pregnancy: A multiparametric approach. Obstet Gynaecol Reprod Med 2017; 27:266-276.

37. Phillips C, Walsh E. Group A streptococcal infection during pregnancy and the postpartum period. Nurs Womens Health 2020;24:13-23.

38. Aguirre AA, Longcore T, Barbieri M, et al. The One Health approach to toxoplasmosis: Epidemiology, control, and prevention strategies. EcoHealth 2019;16:378-390.

39. Paquet C, Yudin MH, Yudin MH, et al. Toxoplasmosis in pregnancy: Prevention, screening, and treatment. J Obstet Gynaecol Can 2013;35:78-79.

40. Peeling RW, Mabey D, Kamb ML, Chen X-S, Radolf JD, Benzaken AS. Syphilis. Nat Rev Dis Primers 2017;3: 17073.

41. Nelson R. Congenital syphilis and other STIs rise in the USA. Lancet Infect Dis 2018;18:1186-1187.

42. The Lancet (Editorial). Congenital syphilis in the USA. Lancet 2018;392:1168.

43. Imanishi M, Routh JA, Klaber M, et al. Estimating the attack rate of pregnancy-associated listeriosis during a large outbreak. Infect Dis Obstet Gynecol 2015;2015:201479.

44. Schantz-Dunn J, Nour NM. Malaria and pregnancy: A global health perspective. Rev Obstet Gynecol 2009;2:186192.

45. De Beaudrap P, Turyakira E, Nabasumba C, et al. Timing of malaria in pregnancy and impact on infant growth and morbidity: A cohort study in Uganda. Malar J 2016;15:92.

46. Harde M, Bhadade R, deSouza R, Jhingan M. Thrombocytopenia in pregnancy nearing term: A clinical analysis. Indian J Crit Care Med 2019;23:503-508.

47. Xiong Y-Q, Tan J, Liu Y-M, et al. The risk of maternal parvovirus B19 infection during pregnancy on fetal loss and fetal hydrops: A systematic review and meta-analysis. J Clin Virol 2019;114:12-20.

48. Jensen IP, Thorsen P, Jeune B, Møller BR, Vestergaard BF. An epidemic of parvovirus B19 in a population of 3596 pregnant women: A study of sociodemographic and medical risk factors. BJOG 2000;107:637-643.

49. Turrini F, Ghezzi S, Pagani I, Poli G, Vicenzi E. Zika virus: A re-emerging pathogen with rapidly evolving public health implications. New Microbiol 2016;39:86-90.

50. Chimelli L, Melo ASO, Avvad-Portari E, et al. The spectrum of neuropathological changes associated with congenital Zika virus infection. Acta Neuropathol 2017;133: 983-999.

51. Poland GA, Kennedy RB, Ovsyannikova IG, Palacios R, Ho PL, Kalil J. Development of vaccines against Zika virus. Lancet Infect Dis 2018;18:e211-e219. 
52. Pereira L. Congenital viral infection: Traversing the uterine-placental interface. Annu Rev Virol 2018;5:273299.

53. Yazigi A, De Pecoulas AE, Vauloup-Fellous C, GrangeotKeros L, Ayoubi J-M, Picone O. Fetal and neonatal abnormalities due to congenital rubella syndrome: A review of literature. J Matern Fetal Neonatal Med 2017;30:274278.

54. Lazzarotto T, Blazquez-Gamero D, Delforge ML, et al. Congenital cytomegalovirus infection: A narrative review of the issues in screening and management from a panel of European experts. Front Pediatr 2020;8: [Epub ahead of print]; DOI: 10.3389/fped.2020.00013.

55. Nelson CS, Jenks JA, Pardi N, et al. HCMV glycoprotein B nucleoside-modified mRNA vaccine elicits antibody responses with greater durability and breadth than MF59adjuvanted gB protein immunization. J Virol 2020; [Epub ahead of print]; DOI: 10.1128/JVI.00186-20.

56. Looker KJ, Magaret AS, May MT, et al. First estimates of the global and regional incidence of neonatal herpes infection. Lancet Glob Health 2017;5:e300-e309.

57. Silasi M, Cardenas I, Kwon J-Y, Racicot K, Aldo P, Mor G. Viral infections during pregnancy. Am J Reprod Immunol 2015;73:199-213.

58. Johnston C, Gottlieb SL, Wald A. Status of vaccine research and development of vaccines for herpes simplex virus. Vaccine 2016;34:2948-2952.

59. Patel CD, Taylor SA, Mehrbach J, Awasthi S, Friedman HM, Leib DA. Trivalent glycoprotein subunit vaccine prevents neonatal herpes simplex virus mortality and morbidity. J Virol 2020; [Epub ahead of print]; DOI: 10.1128/JVI.02163-19.

60. Sweeney EL, Kallapur SG, Meawad S, et al. Ureaplasma species multiple banded antigen (MBA) variation is associated with the severity of inflammation in vivo and in vitro in human placentae. Front Cellular Infect Microbiol 2017; $7: 123$.

61. Biernat-Sudolska M, Bilska-Wilkosz A, Rojek-Zakrzewska D, Zawilińska B, Kosz-Vnenchak M. Evaluation of urease activity by the human Ureaplasma species. Folia Biol 2017;65:142-147.

62. Barton JR, Sibai BM. Severe sepsis and septic shock in pregnancy. Obstet Gynecol 2012;120:689-706.

63. Eschenbach DA. Treating spontaneous and induced septic abortions. Obstet Gynecol 2015;125:1042-1048.

64. Rouse CE, Eckert LO, Muñoz FM, et al. Postpartum endometritis and infection following incomplete or complete abortion: Case definition and guidelines for data collection, analysis, and presentation of maternal immunization safety data. Vaccine 2019;37:7585-7595.

65. Stubblefield PG, Grimes DA. Septic abortion. N Engl J Med 1994;331:310-314.

66. Brunham RC, Gottlieb SL, Paavonen J. Pelvic inflammatory disease. N Engl J Med 2015;372:2039-2048.

67. Lissauer D, Kilby MD, Moss P. Maternal effector T cells within decidua: The adaptive immune response to pregnancy? Placenta 2017;60:140-144.

68. Romero R, Gomez-Lopez N, Winters AD, et al. Evidence that intra-amniotic infections are often the result of an ascending invasion: A molecular microbiological study. J Perinat Med 2019;47:915-931.

69. Tita AT, Andrews WW. Diagnosis and management of clinical chorioamnionitis. Clin Perinatol 2010;37:339354.
70. Gomez-Lopez N, Romero R, Maymon E, et al. Clinical chorioamnionitis at term IX: In vivo evidence of intra-amniotic inflammasome activation. J Perinat Med 2019;47:276-287.

71. Higgins RD, Saade G, Polin RA, et al. Evaluation and management of women and newborns with a maternal diagnosis of chorioamnionitis: Summary of a workshop. Obstet Gynecol 2016;127:426-436.

72. Smaill FM, Grivell RM. Antibiotic prophylaxis versus no prophylaxis for preventing infection after cesarean section. Cochrane Database Syst Rev 2014;CD007482.

73. Mackeen AD, Packard RE, Ota E, Berghella V, Baxter JK. Timing of intravenous prophylactic antibiotics for preventing postpartum infectious morbidity in women undergoing cesarean delivery. Cochrane Database Syst Rev 2014:CD009516.

74. Practice bulletin no. 199: Use of prophylactic antibiotics in labor and delivery: Correction. Obstet Gynecol 2019;134: 883-884.

75. Haas DM, Morgan S, Contreras K, Kimball S. Vaginal preparation with antiseptic solution before cesarean section for preventing postoperative infections. Cochrane Database Syst Rev 2020;4:CD007892.

76. Mackeen AD, Packard RE, Ota E, Speer L. Antibiotic regimens for postpartum endometritis. Cochrane Database Syst Rev 2015;2015:CD001067.

77. Sood G, Argani C, Ghanem KG, Perl TM, Sheffield JS. Infections complicating cesarean delivery. Curr Opin Infect Dis 2018;31:368-376.

78. Gommesen D, Nohr EA, Drue HC, Qvist N, Rasch V. Obstetric perineal tears: Risk factors, wound infection and dehiscence: A prospective cohort study. Arch Gynecol Obstet 2019;300:67-77.

79. Oud L, Watkins P. Necrotizing fasciitis associated with pregnancy: A population-based cohort study. Infect Dis Ther 2014;3:307-320.

80. Dotters-Katz SK, Smid MC, Grace MR, Thompson JL, Heine RP, Manuck T. Risk factors for postpartum septic pelvic thrombophlebitis: A multicenter cohort. Am J Perinatol 2017;34:1148-1151.

81. Garcia J, Aboujaoude R, Apuzzio J, Alvarez JR. Septic pelvic thrombophlebitis: Diagnosis and management. Infect Dis Obstet Gynecol 2006;2006:15614.

82. Tregoning JS, Weiner J, Cizmeci D, et al. Pregnancy has a minimal impact on the acute transcriptional signature to vaccination. NPJ Vaccines 2020;5:29.

83. Keller-Stanislawski B, Englund JA, Kang G, et al. Safety of immunization during pregnancy: A review of the evidence of selected inactivated and live attenuated vaccines. Vaccine 2014;32:7057-7064.

84. Kochhar S, Edwards KM, Ropero Alvarez AM, Moro PL, Ortiz JR. Introduction of new vaccines for immunization in pregnancy: Programmatic, regulatory, safety and ethical considerations. Vaccine 2019;37:3267-3277.

85. Moir D, Gunter K, Lynch L-A, Vogrin S, Said J. Antenatal vaccine uptake: A cross-sectional study investigating factors influencing women's choices in pregnancy. Aust N Z J Obstet Gynaecol 2020; [Epub ahead of print]; DOI: 10.1111/ajo.13146.

86. Murthy NC, Black C, Kahn KE, et al. Tetanus, diphtheria, and acellular pertussis and influenza vaccinations among women with a live birth, internet panel survey, 2017-2018. Infect Dis (Auckl) 2020;13:1178633720904099.

87. Wong A, Opinel A, Combes SJ, Toubiana J, Brisse S. Determining factors for pertussis vaccination policy: A 
study in five EU countries. Vaccines (Basel) 2020;8: [Epub ahead of print]; DOI: 10.3390/vaccines 8010046 .

88. Billington WD. The immunological problem of pregnancy: 50 years with the hope of progress. A tribute to Peter Medawar. J Reprod Immunol 2003;60:1-11.

89. Ma'ayeh M, Rood KM, Kniss D, Costantine MM. Novel interventions for the prevention of preeclampsia. Curr Hypertens Rep 2020;22:17.

90. Dutta S, Kumar S, Hyett J, Salomon C. Molecular targets of aspirin and prevention of preeclampsia and their potential association with circulating extracellular vesicles during pregnancy. Int J Mol Sci 2019;20: [Epub ahead of print]; DOI: $10.3390 /$ ijms20184370.

91. Ngo TTM, Moufarrej MN, Rasmussen MH, et al. Noninvasive blood tests for fetal development predict gestational age and preterm delivery. Science 2018;360: 1133-1136.

92. Peterson LS, Stelzer IA, Tsai AS, et al. Multiomic immune clockworks of pregnancy. Semin Immunopathol 2020; [Epub ahead of print]; DOI: 10.1007/s00281-019-00772-1.
93. Creanga AA, Syverson C, Seed K, Callaghan WM. Pregnancy-related mortality in the United States, 20112013. Obstet Gynecol 2017;130:366-373.

94. Petersen EE, Davis NL, Goodman D, et al. Vital signs: Pregnancy-related deaths, United States, 2011-2015, and strategies for prevention, 13 states, 2013-2017. MMWR Morb Mortal Wkly Rep 2019;68:423-429.

Address correspondence to: Mercy PrabhuDas, PhD National Institute of Allergy and Infectious Diseases National Institutes of Health 5601 Fishers Lane, Room 7 B57 Rockville, MD 20852

USA

E-mail: mprabhudas@niaid.nih.gov 